\title{
Epidemiological relationships between the common cold and exacerbation frequency
} in COPD

\author{
J.R. Hurst, G.C. Donaldson, T.M.A. Wilkinson, W.R. Perera and J.A. Wedzicha
}

ABSTRACT: Higher exacerbation incidence rates in chronic obstructive pulmonary disease (COPD) are associated with more rapid decline in lung function and poorer quality of life, yet the mechanisms determining susceptibility to exacerbation remain ill-defined. The same viruses responsible for common colds are frequently isolated during exacerbations. The current authors hypothesised that exacerbation frequency may be associated with an increased frequency of colds, and investigated whether increased exacerbation frequency was associated with increased acquisition of colds, or a greater likelihood of exacerbation once a cold has been acquired.

A total of 150 patients with COPD completed diary cards recording peak expiratory flow, and respiratory and coryzal symptoms for a median 1,047 days. Annual cold and exacerbation incidence rates (cold and exacerbation frequency) were calculated, and the relationships between these variables were investigated.

This analysis is based on 1,005 colds and 1,493 exacerbations. Frequent exacerbators (i.e. those whose exacerbation frequency was greater than the median) experienced significantly more colds than infrequent exacerbators (1.73 versus $0.94 \cdot \mathrm{yr}^{-1}$ ). The likelihood of exacerbation during a cold was unaffected by exacerbation frequency. Patients experiencing frequent colds had a significantly higher exposure to cigarette smoke (46 versus 33 pack-yrs).

Exacerbation frequency in chronic obstructive pulmonary disease is associated with an increased frequency of acquiring the common cold, rather than an increased propensity to exacerbation once a cold has been acquired.

KEYWORDS: Chronic obstructive pulmonary disease, common cold, exacerbation, respiratory viruses

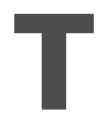
he course of chronic obstructive pulmonary disease (COPD) is punctuated by episodes of acute deterioration in respiratory health, termed "exacerbations", which account for much of the morbidity, mortality, hospital admissions and healthcare costs associated with this condition [1-3]. Exacerbations also affect the progression of disease, such that patients experiencing more frequent exacerbations have greater airway inflammation [4], a faster decline in lung function [5] and poorer quality of life [1]. Exacerbations are, therefore, important events in the natural history of COPD, but the mechanisms determining susceptibility to exacerbation remain poorly understood.

Respiratory viruses, especially rhinoviruses, are an important cause of exacerbation and may be isolated in $>50 \%$ of cases [6]. Rhinoviruses are also the viruses most frequently associated with the common cold [7]. It has been previously reported that $50 \%$ of exacerbations are associated with coryzal symptoms at the time of presentation [8], and that such exacerbations, or those in which a virus has been isolated from the respiratory tract, are of greater severity when assessed by changes in symptoms, lung function, and both airway and systemic inflammatory markers [8-11]. This suggests that common cold viruses are important in both causing and determining the severity of exacerbations. However, the relationship between exacerbation frequency and incidence of the common cold in COPD has not been previously studied.

The current authors hypothesised that frequent exacerbation in COPD may be associated with increased incidence of the common cold. The aim of the study was to test this hypothesis, and explore potential underlying mechanisms, using an epidemiological approach in an established cohort with well-characterised disease.

\section{AFFILIATIONS}

Academic Unit of Respiratory Medicine, Royal Free and University College Medical School, London, UK.

CORRESPONDENCE

J.A. Wedzicha

Academic Unit of Respiratory

Medicine

Royal Free and University College Medical School

Hampstead

London

NW3 2QG

UK

Fax: 442074726140

E-mail:

j.a.wedzicha@medsch.ucl.ac.uk

Received:

April 122005

Accepted after revision:

July 182005

SUPPORT STATEMENT

This study was funded by the Joint Research Board, St. Bartholomew's Hospital, London, UK.

European Respiratory Journal

Print ISSN 0903-1936

Online ISSN 1399-3003 
Identification of the factors associated with increased susceptibility to exacerbation in COPD is of importance in the appropriate targeting of preventative therapies.

\section{METHODS}

\section{Study subjects}

A total of 150 patients enrolled in The East London COPD cohort were studied during the period of 1995 to 2003. These patients were enrolled at The London Chest Hospital, following recruitment from primary and secondary care. The patients recorded daily peak expiratory flow (PEF; Mini-Wright; Clement Clarke, Harlow, UK), time spent outdoors, and increase in respiratory and coryzal symptoms on diary cards. The entry criteria of the study comprised a post-bronchodilator forced expiratory volume in one second (FEV1) $<80 \%$ predicted, FEV1/forced vital capacity (FVC) ratio $<70 \%, \beta_{2^{-}}$ agonist reversibility on FEV1 $<200 \mathrm{~mL}$ and/or $15 \%$, and the absence of other significant respiratory pathology. At recruitment, spirometry and arterialised ear-lobe capillary blood gas analysis were performed, and information regarding therapy recorded. In total, 141 of the 150 patients were taking regular inhaled corticosteroids. Approximately $80 \%$ of patients received influenza vaccination on an annual basis. Detailed information on social contacts was available for 55 patients as described below. These 55 subjects did not differ in terms of age, sex, FEV1 or exacerbation frequency from the remaining 95 participants. Written informed consent was obtained and the study had appropriate ethics committee approval.

The baseline characteristics of the 150 patients are described in table 1, which illustrates that the cohort had moderately severe COPD with a median FEV1 of $39.6 \%$ pred. Forty-seven $(31 \%)$ patients continued to smoke at recruitment and, of the remaining 103 patients, 97 were ex-smokers. The median (interquartile range (IQR)) follow-up period was 1,047 (697$1,795)$ days.

\section{Definition of an exacerbation}

An exacerbation was defined according to the current authors' previous work [1], based on that first described by ANTHONISEN et al. [12], and validated against important outcomes including

\section{TABLE 1 Clinical characteristics of the studied patients}

\begin{tabular}{|c|c|}
\hline Subjects $n$ & 150 \\
\hline Males/females $n$ & $101 / 49$ \\
\hline Age yrs & $68.4(62.6-73.7)$ \\
\hline 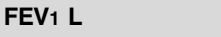 & $0.98(0.74-1.30)$ \\
\hline FEV $_{1} \%$ pred & $39.6(28.2-51.1)$ \\
\hline FVC L & $2.44(1.82-2.93)$ \\
\hline FEV $_{1} /$ FVC $\%$ & $42.3(34.5-53.1)$ \\
\hline PEF L· $\min ^{-1}$ & $174(137-250)$ \\
\hline $\mathrm{Pa}_{1} \mathrm{O}_{2} \mathrm{kPa}$ & $9.0(8.2-9.6)$ \\
\hline $\mathrm{Pa}, \mathrm{CO}_{2} \mathrm{kPa}$ & $5.8(5.4-6.4)$ \\
\hline Smoking pack-yrs & $42(32-50)$ \\
\hline
\end{tabular}

Data are presented as median (interquartile range), unless otherwise stated FEV1: forced expiratory volume in one second; \% pred: \% predicted; FVC forced vital capacity; PEF: peak expiratory flow; $\mathrm{Pa}, \mathrm{O}_{2}$ : arterial oxygen tension $\mathrm{Pa}, \mathrm{CO}_{2}$ : arterial carbon dioxide tension. lung function decline [5] and quality of life [1]. Patients were instructed to record any increase over their usual degree of daily symptoms on diary cards. The patients did not record symptoms when these were of their usual severity. The symptoms recorded were termed major (dyspnoea, sputum volume or sputum purulence) and minor (cough, wheeze, sore throat or coryza). Coryza was defined as one or more of the following: runny or blocked nose, post-nasal drip or sneezing. An exacerbation was defined as the onset of two or more new or worsening symptoms, on $\geqslant 2$ consecutive days, at least one symptom of which must be major.

Exacerbation severity was assessed using a symptom score. Each symptom, major and minor, was binary coded as present/increased over baseline (1) or absent/not increased (0) and summed. This symptom score was calculated daily throughout the exacerbation. When the value of the 3-day moving average of the symptom score had returned to baseline (defined as the mean recorded on days 8-14 preceding the onset), the exacerbation was considered to be resolved. Therefore, the recovery time for symptoms is the time from exacerbation onset to the return of the symptom score to baseline. Similarly, the recovery time for PEF at exacerbation was defined as the time from exacerbation onset to the day on which a 3-day moving average of PEF returned to baseline (defined as the mean PEF recorded on days 8-14 preceding the onset of exacerbation).

Exacerbations may or may not be associated with a cold. The present authors did not wish to make prior assumptions about the relative timing of upper and lower respiratory tract symptoms during such events and, based on the reported duration of symptoms during natural colds and a previous report on the relative timing of coryzal symptoms during exacerbations [9], defined exacerbations as associated with a cold, necessarily arbitrarily, as when increased coryzal symptoms were recorded at any time during the period of 3 days prior to 7 days following the onset of exacerbation.

The annual exacerbation incidence rate for each patient, the exacerbation frequency, was calculated and the median value used to divide patients into two equally sized groups, termed frequent and infrequent exacerbators (i.e. exacerbation frequency greater and less than the median, respectively).

\section{Definition of a cold}

In a manner analogous to the previous definition of exacerbation, a cold was defined as $\geqslant 2$ days of recording new or increased coryzal symptoms (one or more of runny or blocked nose, post-nasal drip and sneezing). Colds may or may not be associated with an exacerbation. The term upper airway cold was used to refer to a cold (defined as above), but which did not meet the definition of exacerbation. An upper airway cold was judged to have resolved when the increased coryzal symptoms were no longer recorded by the patient, and the symptom duration of an upper airway cold was calculated as the time from onset to resolution of these symptoms. If the patient stopped recording increased coryzal symptoms for up to 3 days and then restarted, the cold was considered as continuous throughout this period. The PEF recovery time for an upper airway cold was defined as the time from symptom onset to the day on which a 3-day moving average of PEF had 
returned to baseline (defined previously). The median annual incidence of colds, the cold frequency, was used to divide patients into two equally sized groups experiencing frequent and infrequent colds (i.e. cold frequency greater and less than the median, respectively).

\section{Analysis}

Data are expressed as median (IQR), and comparisons were made by Wilcoxon sign rank test or Spearman correlation as appropriate. Where the characteristics of patients divided by cold or exacerbation frequency have been investigated, the unit of analysis has been the individual patient, thus avoiding bias from those patients contributing a greater number of data points. Where the severity of exacerbations (all, with, or without colds) and upper airway colds has been compared, and if a patient had more than one event of any type, then the data was averaged, again to avoid bias from multiple events in the same patient. Tests of seasonality (winter versus summer) were performed using a generalised estimating equation approach, with allowance for repeated measures on the same patient. Year of study was included as a covariate to allow for changes over time. A probability of error $\leqslant 5 \%$ was considered statistically significant.

\section{RESULTS}

\section{Prevalence and seasonality of colds and exacerbations}

During the period of study, there were a total of 1,005 colds and 1,493 exacerbations. Forty-three per cent of colds (433 in total) fulfilled the definition of exacerbation, and $29 \%$ of exacerbations (433 in total) were associated with a cold. The median (IQR) exacerbation frequency was $2.56 \cdot$ patient $^{-1} \cdot \mathrm{yr}^{-1}$ (1.55-3.83). The median cold frequency was $1.30 \cdot$ patient $^{-1} \cdot \mathrm{yr}^{-1}$ (0.50-2.57). The prevalence of both colds and exacerbations peaked during the winter, and followed a similar seasonal pattern throughout the year.

\section{Clinical features of upper airway colds and exacerbations}

The clinical features of upper airway colds and exacerbations are reported in table 2. Exacerbations associated with colds were the more severe, as reflected by a greater rise in symptoms at onset, a longer recovery time in symptom score, and a trend to a greater fall in PEF at onset. Symptoms and changes in PEF were more severe, and recovered significantly more slowly from an exacerbation than an upper airway cold. The time course of changes in PEF and symptom score during upper airway colds and exacerbations are illustrated in figure 1. For exacerbations associated with a cold, coryzal symptoms occurred prior to the onset of exacerbation in $84 \%$ of cases.

\section{Relationships between exacerbation frequency and colds}

The relationships between colds and exacerbation frequency are reported as the validated definition in table 3. Frequent exacerbators experienced significantly more colds, and significantly more exacerbations associated with a cold than the infrequent exacerbators (1.73 versus $0.94 \cdot \mathrm{yr}^{-1}, \mathrm{p}=0.003$; and 0.95 versus $0.45 \cdot \mathrm{yr}^{-1}, \mathrm{p}<0.0001$, respectively). Similarly, patients with frequent colds experienced significantly more exacerbations than those with infrequent colds (3.23 versus $2.10 \cdot \mathrm{yr}^{-1}$, $\mathrm{p}<0.001$ ). The data showing that upper airway colds were also more common in frequent exacerbators did not reach statistical significance. There was no difference between the frequent and infrequent exacerbators in the number of colds associated with exacerbation expressed as a percentage of total colds $(54 \%$ versus $50 \%, \mathrm{p}=0.135)$.

The current authors acknowledge (and discuss later) the appearance of coryzal symptoms in both the definition of colds and exacerbations, and, therefore, repeated the analyses excluding those 162 exacerbations in which the definition of exacerbation comprised solely one major symptom plus coryza. These data are reported as the alternative definition in table 3, with no qualitative change to the findings of the study.

\section{Characteristics of patients by cold frequency}

The clinical characteristics of the 150 patients, stratified by cold and exacerbation frequencies, are reported in table 4 . Patients experiencing frequent colds were found to have a greater total smoke exposure (46 versus 33 pack-yrs, $p=0.023$ ). No significant relationships were found between cold frequency and age, sex, FEV1, FVC, baseline respiratory or nasal symptoms, time spent outdoors, dose of inhaled corticosteroid or influenza vaccination status.

Detailed social contact data were available for a subset of 55 patients. Of these, 18 (33\%) lived alone, 27 (49\%) with one other person, and $10(18 \%)$ with two or more others. The median (IQR) number of visitors into the home was $2(2-5)$ per week, and the median number of trips made outside the home 5 (2-7)

TABLE 2 Comparison of the severity of upper airway colds and all exacerbations, and exacerbations both with and without colds

\begin{tabular}{|c|c|c|c|c|}
\hline Upper airway colds & All exacerbations & p-value ${ }^{\#}$ & $\begin{array}{l}\text { Exacerbations } \\
\text { without colds }\end{array}$ & $\begin{array}{l}\text { Exacerbations } \\
\text { with colds }\end{array}$ \\
\hline
\end{tabular}

\begin{tabular}{|c|c|c|c|c|c|c|}
\hline Fall in PEF at onset $L \cdot \min ^{-1}$ & $-2.3(-9.4-3.4)$ & $-9.3(-15.3--4.5)$ & $<0.001$ & $-8.2(-15.2--2.9)$ & $-11.4(-20.2--2.9)$ & 0.090 \\
\hline PEF recovery time days & $5.3(2.5-11.5)$ & $9.5(6.4-14.3)$ & $<0.001$ & $8.8(5.3-14.0)$ & $10.9(5.2-16.6)$ & 0.267 \\
\hline $\begin{array}{l}\text { Symptom rise at onset } \\
\text { units }\end{array}$ & $1.0(0.7-1.3)$ & $2.0(1.5-2.5)$ & $<0.001$ & $1.7(1.3-2.2)$ & $2.7(-2.7-3.5)$ & $<0.001$ \\
\hline $\begin{array}{l}\text { Symptom recovery time } \\
\text { days }\end{array}$ & $8.0(5.0-12.5)$ & $12.0(8.0-16.0)$ & $<0.001$ & $9.8(6.0-15.6)$ & $13.4(8.0-18.4)$ & 0.001 \\
\hline
\end{tabular}

Data are presented as median (interquartile range), unless otherwise stated. PEF: peak expiratory flow. \#: upper airway colds versus all exacerbations; ${ }^{\bullet}$ : exacerbations without colds versus exacerbations with colds. 

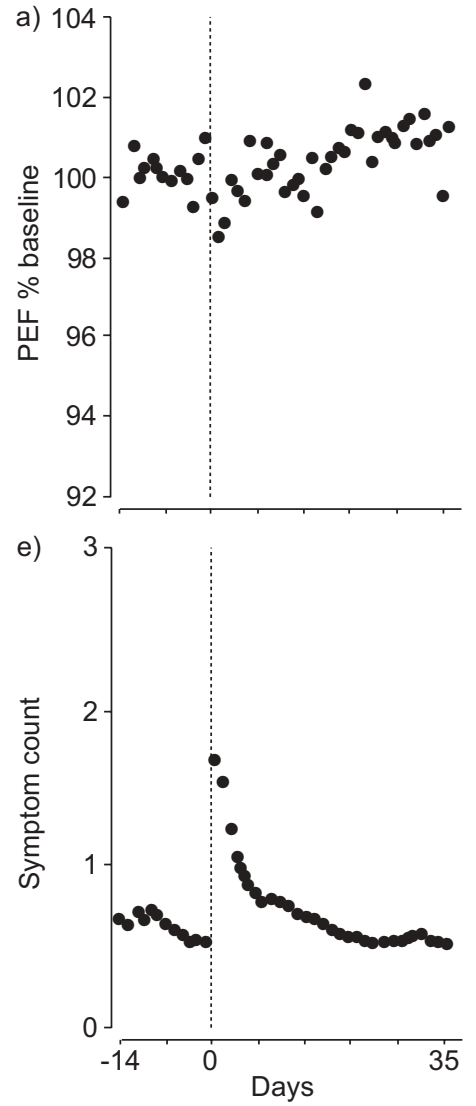
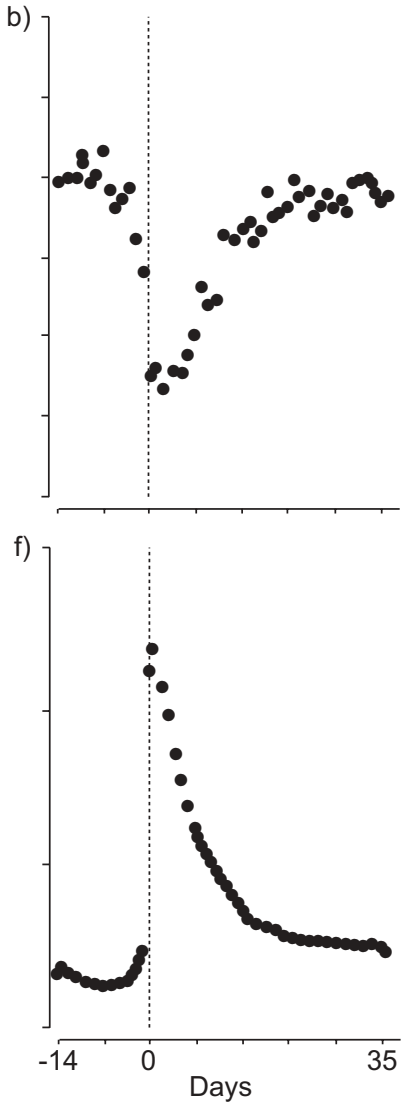
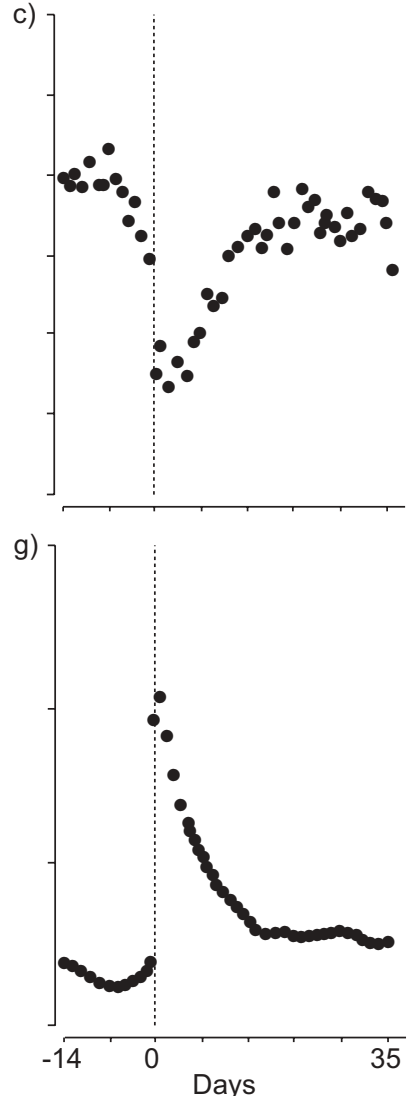
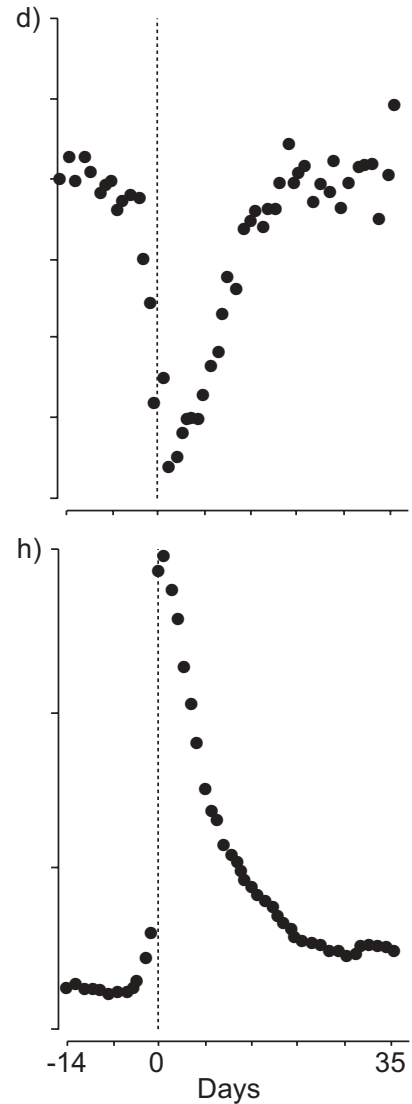

FIGURE 1. Time course of changes in peak expiratory flow (PEF) and symptom score (count) in patients with chronic obstructive pulmonary disease during upper airway colds $(a, e)$, all exacerbations (b, f), exacerbations without colds $(c, g)$ and exacerbations with colds $(d, h)$. Data are expressed as the mean value of the means calculated for each of 150 patients. The statistical comparison is reported in table 2 .

per week. There were no significant relationships between cold frequency and either the number of people living at home $(\rho=-0.080, p=0.560)$, the number of visitors into the home $(\rho=0.032, p=0.826)$, or the number of trips made outside the home $(\rho=0.038, p=0.796)$.

Twenty-one (14\%) patients never reported a cold. In comparison with the population who had experienced colds, these subjects had a trend to a lower exacerbation frequency (2.44 versus $\left.2.63 \cdot \mathrm{yr}^{-1}, \mathrm{p}=0.080\right)$. They also had a significantly higher FEV1 (1.00 versus $0.701, p=0.001)$, but did not differ in any of the other clinical variables assessed in these patients (table 4).

The ratio of colds associated with exacerbations to total colds was calculated to assess the likelihood of a cold being associated with exacerbation. In addition to being independent of exacerbation frequency as described previously, this ratio was also unaffected by the clinical indices listed in table 4 .

\section{TABLE 3 Relationships between colds and exacerbation frequency in chronic obstructive pulmonary disease ${ }^{\#}$}

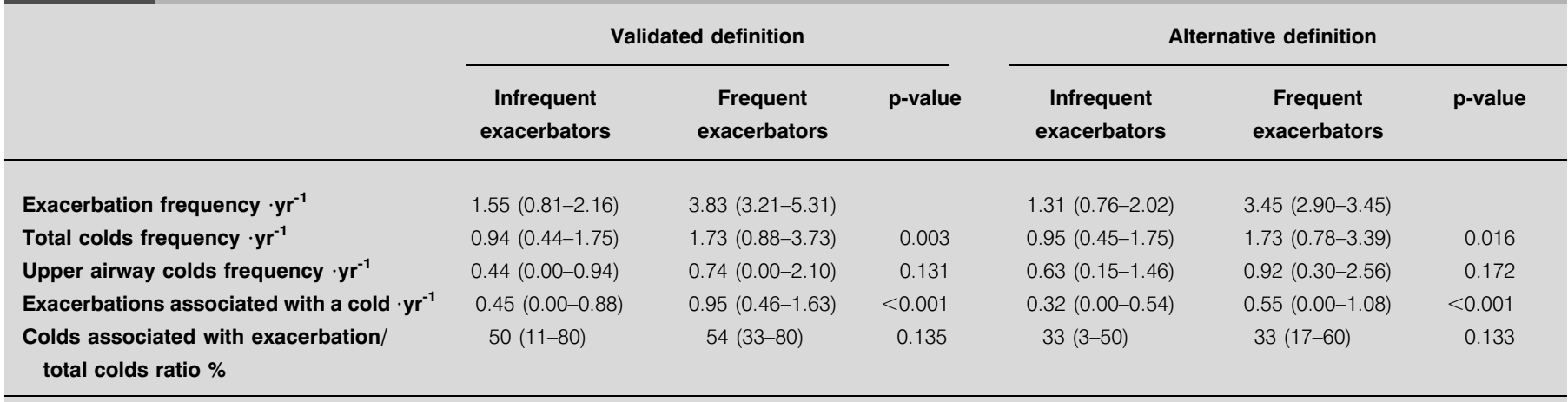

Data are presented as median (interquartile range), unless otherwise stated. ${ }^{\#}$ : each group $n=75$. 
TABLE 4 Comparison of the clinical characteristics in the 150 patients stratified by exacerbation and cold frequency\#

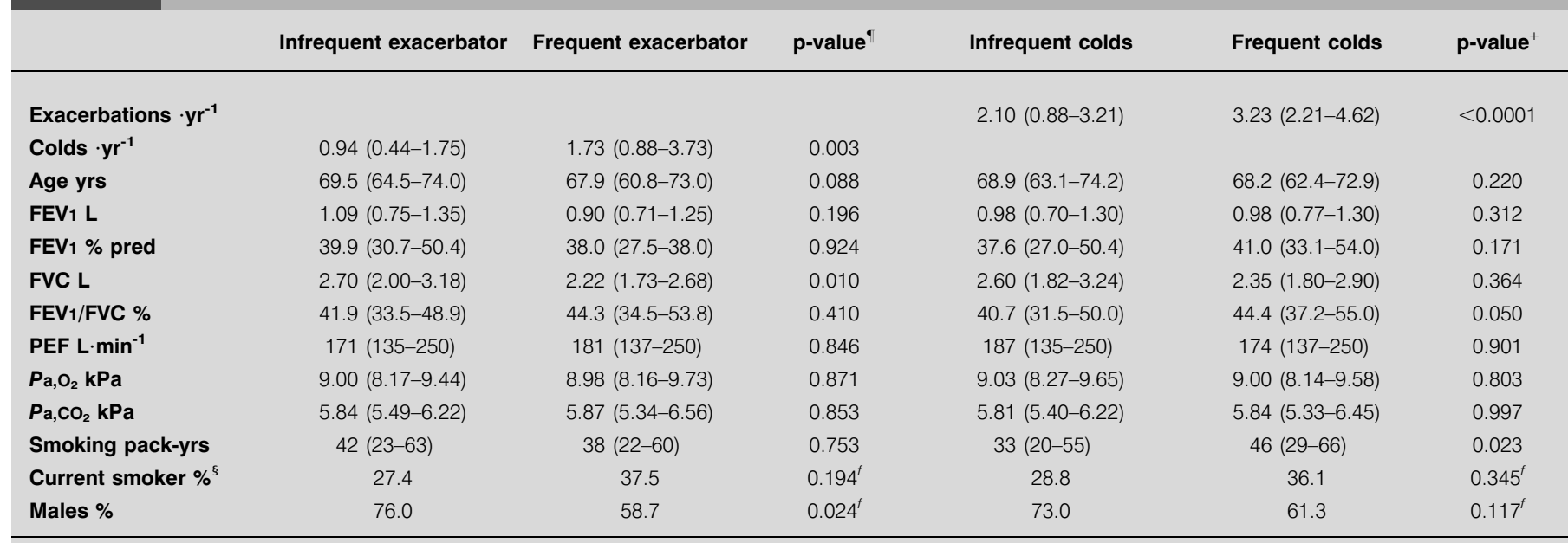

Data are presented as median (interquartile range), unless otherwise stated. Infrequent exacerbators were defined as having an exacerbation frequency of $\leqslant 2.56 \cdot y r^{-1}$, whereas frequent exacerbators had a frequency of $>2.56 \cdot \mathrm{yr}^{-1}$. Patients with infrequent colds had a cold frequency of $\leqslant 1.30 \cdot \mathrm{yr}^{-1}$, whereas those with frequent colds had a frequency of $>1.30 \cdot \mathrm{yr}^{-1}$. FEV1: forced expiratory volume in one second; \% pred: per cent predicted; FVC: forced vital capacity; PEF: peak expiratory flow; $P a, \mathrm{O}_{2}$ : arterial oxygen tension; $\mathrm{Pa}_{1} \mathrm{CO}_{2}$ : arterial carbon dioxide tension. ${ }^{\#}$ : each group $\mathrm{n}=75$; ${ }^{\natural}$ : infrequent versus frequent exacerbator; ${ }^{+}$: infrequent versus frequent colds; ${ }^{\text {s. }}$ : at recruitment; ${ }^{f}$ : using Chi-squared analysis.

\section{DISCUSSION}

The new and major findings of this study are that exacerbation frequency in COPD is related to frequency of the common cold, and that increased exacerbation frequency relates to an intrinsically greater risk of acquiring colds, rather than an increased likelihood of exacerbation once a cold has been acquired. Furthermore, the incidence of colds is related to the extent of cigarette-smoke exposure, and the current authors have described, for the first time, the clinical features of colds in patients with COPD. Therefore, these data inform on factors that are relevant to exacerbation susceptibility in COPD, a topic of considerable clinical importance.

There are no previous studies examining the incidence of colds in patients with COPD stratified by exacerbation frequency. Indeed, given the conflicting results of previous studies comparing the incidence of respiratory viral infections in patients with COPD versus control subjects, there is a need for further data in this area. The most recent work, by GREENBERG et al. [13], suggested that whilst patients with COPD experience more total episodes of respiratory illness than age-matched control subjects (largely exacerbations of COPD), there was no excess incidence of respiratory viral infections. This contradicted a number of older studies, including that by MONTO et al. [14], who reported that patients with chronic bronchitis did have a higher incidence of serologically proven rhinoviral infections. In addition, a study investigating a rhinovirus outbreak at a residential care facility found that patients with COPD were over-represented in those acquiring infection [15], suggesting that patients with COPD are indeed more susceptible to respiratory viral infections.

The current data demonstrate an annual cold frequency in this population with COPD of $1.3 \cdot$ patient $^{-1} \cdot \mathrm{yr}^{-1}$, and $43 \%$ of colds were associated with lower respiratory tract symptoms sufficient to meet the present authors' definition of exacerbation.
The incidence and clinical features of upper respiratory tract viral infection in community studies of the elderly have been reported by NicHOLSON and coworkers [16, 17]. Here, the annual incidence rate was $1.2 \cdot$ patient $^{-1} \cdot \mathrm{yr}^{-1}$, similar to the current data, and, in $63 \%$ of patients with documented rhinoviral infections, there was evidence of lower respiratory tract involvement. The definition of lower respiratory tract involvement in the latter studies was less stringent than that defining exacerbation in the present report. Therefore, it is suggested, in agreement with GREENBERG et al. [13], that COPD patients as a group are not more susceptible to respiratory viral infections, and, in agreement with NiCHOLSON and coworkers $[16,17]$, that patients with COPD do not appear more likely to develop lower respiratory tract symptoms during such events than other elderly subjects. However, the current authors have shown that cold frequency in COPD is variable, and this masks an important effect in frequent exacerbators who do indeed have an increased frequency of colds.

Studies in asthma, a disease also characterised by inflammatory airflow obstruction, have reported that coryzal symptoms are evident in $>70 \%$ of exacerbations [18]. Subsequently, a prospective case-control study by CORNE et al. [19] demonstrated that whilst asthmatics are not at a higher risk of acquiring respiratory viruses, the lower respiratory tract consequences of such infections occur with greater frequency and severity. This suggests that an underlying allergic ( $\mathrm{T}$ helper 2 type) airway inflammation does not predispose to acquiring respiratory viruses, but does predispose to the lower respiratory tract consequences of viral infection.

The current findings in COPD suggest that an alternative mechanism is operating in those patients who are susceptible to frequent exacerbations. It has been demonstrated that frequent exacerbators experience more frequent colds. The present authors hypothesised that this might conceivably be 
due to any one or a combination of three mechanisms: patients with frequent colds may be coming into contact with more viruses in the community; such patients may be intrinsically more susceptible to acquiring respiratory viruses; or once a cold has been acquired, it may be that the host-virus interaction in these patients is such that exacerbation is more likely. There was no suggestion that the frequent exacerbators were more likely to have greater community exposure to viruses, as assessed using the current data on social activities and contacts. Also, the ratio of colds associated with exacerbations to total colds was not dependent on exacerbation frequency. That is to say, once a cold has been acquired, the present data do not support the hypothesis that an altered host-virus interaction affects the likelihood of exacerbation in the frequent exacerbators. Therefore, these data suggest, in contrast to the susceptibility reported in asthmatic airways, that frequent exacerbators are predisposed to the acquisition of colds rather than to a greater risk of exacerbation during a cold.

It is interesting to speculate on the mechanism underlying an increased frequency of the common cold in frequent exacerbators. It is known that such patients have increased lower airway inflammation in the stable state [4], and recent reports have suggested that COPD is also associated with increased nasal inflammation [20-22]. Inflammation results in the upregulation of various cell surface molecules, including intercellular adhesion molecule (ICAM)-1, which also functions as the receptor for the major type of rhinovirus [23]. The current authors have recently reported that the degree of upper airway inflammation in COPD is related to the degree of lower airway inflammation [22], and, therefore, increased ICAM-1 expression in the upper airway of the frequent exacerbators may account for these findings. These data suggest that the upper airway in COPD deserves further study.

Patients at an increased risk of acquiring colds had a greater total smoke exposure. Active smoking has previously been associated with both an increased risk of acquiring common cold viruses, and of symptoms during infection [24]. Whilst a relationship between colds and smoking status in the present study was not found, this may be because so few of the studied patients continued to smoke. Smoking is known to induce nasal inflammatory changes [21], and it is possible that the greater smoke exposure in these patients resulted in greater nasal inflammation. However, the relationships between nasal inflammatory indices and the extent of smoking in COPD have not been studied.

The present study reports that $29 \%$ of exacerbations were associated with a cold, lower than in previous data from this cohort, where up to $50 \%$ of exacerbations were associated [8]. This is probably due to the more stringent definition of exacerbation associated with a cold in the present study. The figure of $29 \%$ is also lower than reports on the prevalence of respiratory viruses isolated from clinical specimens at the time of exacerbation. At least for rhinovirus, the most common isolate, evidence from experimental studies suggests that only $75 \%$ of subjects becoming infected develop symptomatic colds [25]. It is, therefore, quite possible that higher rates of viral isolation may be present at exacerbation than are reflected in the presence of coryzal symptoms.
The strengths and limitations of this study should be discussed. The current authors have collected daily data in an established cohort of patients with well-characterised COPD. Using an epidemiological approach has enabled the study of $>1,000$ colds and $\sim 1,500$ exacerbations. Whilst confirmatory virological studies were not performed and indeed would not be practical in 2,500 events, it has been previously reported that the recording of increased coryzal symptoms by the present patients is associated with the isolation of a respiratory virus [10]. A further point to consider is the validity of definitions used. The currently used definition of exacerbation has been validated against important outcome measures in COPD, including lung function decline [5] and quality of life [1]. There is, however, no widely accepted definition of a cold. A cold was defined in an analogous way to exacerbation and, whilst it is known that patients are capable of self-diagnosing the common cold with a high percentage of confirmatory viral isolation [7, 26-28], specific valedictory evidence cannot be presented in the current cohort using this definition. It is suggested, however, that using a clinical diagnosis of a cold represents a pragmatic approach, given that, even with sophisticated viral diagnostic techniques, many such illnesses remain unattributable to specific pathogens [7]. The current analysis of social contact was restricted to those patients in whom detailed information was available. Thus, whilst these patients did not differ from the remaining cohort, the possibility of failing to detect more subtle differences in social contacts cannot be excluded. Finally, the present authors acknowledge an inherent tautology in that increased coryzal symptoms (the definition of a cold) also appear as a minor criterion in the definition of an exacerbation. Acknowledging this theoretical concern, the analyses were repeated, excluding the 162 exacerbations in which the definition of exacerbation comprised solely one major symptom plus coryza. The major results of the study were qualitatively unaffected, as reported in table 3. Therefore, given that a major strength of this study is the use of a previously validated exacerbation definition, data from all 1,493 exacerbations were primarily presented.

The suggestion that susceptibility to exacerbation in COPD is, at least in part, driven by an increased susceptibility to acquiring respiratory viral infections is of considerable clinical importance. Exacerbations are significant events in COPD, contributing to morbidity, mortality, hospital admission, healthcare costs, and affecting progression of disease as assessed by the rate of decline in FEV1 [1-3, 5]. New approaches to reduce the burden of these episodes are urgently required and the present data suggest, for example, that strategies to prevent exacerbations might most usefully target viral acquisition. Moreover, the present confirmation that exacerbations associated with colds are the most severe emphasises the need for novel therapies to prevent or treat such events. At present, with the exception of influenza vaccination, there are no interventions available that specifically target viral acquisition or replication in an attempt to reduce the effects of exacerbations in COPD.

In conclusion, the current authors have shown that exacerbation frequency in chronic obstructive pulmonary disease is associated with frequency of the common cold, and that an increased exacerbation frequency is associated with a heightened risk of acquiring colds, rather than an increased 
likelihood of exacerbation once a cold has been acquired. The data provide information on the mechanisms of exacerbation in chronic obstructive pulmonary disease and have important implications for the development of novel therapeutic strategies to treat this prevalent and debilitating disease.

\section{ACKNOWLEDGEMENTS}

The authors gratefully acknowledge the assistance of all the Research Fellows, not individually named as authors on this paper, who have worked in the Academic Unit of Respiratory Medicine (St. Bartholomew's and The Royal London School of Medicine, London, UK) and collected sections of data that have made this paper possible.

\section{REFERENCES}

1 Seemungal TAR, Donaldson GC, Paul EA, Bestall JC, Jeffries DJ, Wedzicha JA. Effect of exacerbation on quality of life in patients with chronic obstructive pulmonary disease. Am J Respir Crit Care Med 1998; 157: 1418-1422.

2 Connors AF Jr, Dawson NV, Thomas C, et al. Outcomes following acute exacerbations of severe chronic obstructive lung disease. Am J Respir Crit Care Med 1996; 154: 959-967.

3 Sullivan SD, Ramsey SD, Lee TA. The economic burden of COPD. Chest 2000; 117: Suppl. 2, 5S-9S.

4 Bhowmik A, Seemungal TAR, Sapsford RJ, Wedzicha JA. Relation of sputum inflammatory markers to symptoms and lung function changes in COPD exacerbations. Thorax 2000; 55: 114-120.

5 Donaldson GC, Seemungal TAR, Bhowmik A, Wedzicha JA. Relationship between exacerbation frequency and lung function decline in chronic obstructive pulmonary disease. Thorax 2002; 57: 847-852.

6 Rohde G, Wiethege A, Borg I, et al. Respiratory viruses in exacerbations of chronic obstructive pulmonary disease requiring hospitalisation: a case-control study. Thorax 2003; 58: $37-42$.

7 Heikkinen T, Jarvinen A. The common cold. Lancet 2003; 361: 51-59.

8 Seemungal T, Harper-Owen R, Bhowmik A, et al. Respiratory viruses, symptoms, and inflammatory markers in acute exacerbations and stable chronic obstructive pulmonary disease. Am J Respir Crit Care Med 2001; 164 : 1618-1623.

9 Seemungal TAR, Donaldson GC, Bhowmik A, Jeffries DJ, Wedzicha JA. Time course and recovery of exacerbations in patients with chronic obstructive pulmonary disease. Am J Respir Crit Care Med 2000; 161: 1608-1613.

10 Seemungal TAR, Harper-Owen R, Bhowmik A, Jeffries DJ, Wedzicha JA. Detection of rhinovirus in induced sputum at exacerbation of chronic obstructive pulmonary disease. Eur Respir J 2000; 16: 677-683.

11 Wedzicha JA, Seemungal TA, MacCallum PK, et al. Acute exacerbations of chronic obstructive pulmonary disease are accompanied by elevations of plasma fibrinogen and serum IL-6 levels. Thromb Haemost 2000; 84: 210-215.

12 Anthonisen NR, Manfreda J, Warren CP, Hershfield ES, Harding GK, Nelson NA. Antibiotic therapy in exacerbations of chronic obstructive pulmonary disease. Ann Intern Med 1987; 106: 196-204.

13 Greenberg SB, Allen M, Wilson J, Atmar RL. Respiratory viral infections in adults with and without chronic obstructive pulmonary disease. Am J Respir Crit Care Med 2000; 162: 167-173.

14 Monto AS, Bryan ER. Susceptibility to rhinovirus infection in chronic bronchitis. Am Rev Respir Dis 1978; 118: 1101-1103.

15 Wald TG, Shult P, Krause P, Miller BA, Drinka P, Gravenstein S. A rhinovirus outbreak among residents of a long-term care facility. Ann Intern Med 1995; 123: 588-593.

16 Nicholson KG, Kent J, Hammersley V, Cancio E. Acute viral infections of upper respiratory tract in elderly people living in the community: comparative, prospective, population based survey of disease burden. BMJ 1997; 315: 1060-1064.

17 Nicholson KG, Kent J, Hammersley V, Cancio E. Risk factors for lower respiratory complications of rhinovirus infections in elderly people living in the community: prospective cohort study. BMJ 1996; 313: 1119-1123.

18 Nicholson KG, Kent J, Ireland DC. Respiratory viruses and exacerbations of asthma in adults. BMJ 1993; 307: 982-986.

19 Corne JM, Marshall C, Smith S, et al. Frequency, severity, and duration of rhinovirus infections in asthmatic and non-asthmatic individuals: a longitudinal cohort study. Lancet 2002; 359: 831-834.

20 Nihlen U, Andersson M, Lofdahl C-G, Persson CG, Montnemery P, Greiff L. Nasal neutrophil activity and mucinous secretory responsiveness in COPD. Clin Physiol Funct Imaging 2003; 23: 138-142.

21 Vachier I, Vignola AM, Chiappara G, et al. Inflammatory features of nasal mucosa in smokers with and without COPD. Thorax 2004; 59: 303-307.

22 Hurst JR, Wilkinson TMA, Perera WR, Donaldson GC, Wedzicha JA. Relationships among bacteria, upper airway, lower airway, and systemic inflammation in COPD. Chest 2005; 127: 1219-1226.

23 Staunton DE, Merluzzi VJ, Rothlein R, Barton R, Marlin SD, Springer TA. A cell adhesion molecule, ICAM-1, is the major surface receptor for rhinoviruses. Cell 1989; 56: 849-853.

24 Cohen S, Tyrrell DAJ, Russell MAH, Jarvis MJ, Smith AP. Smoking, alcohol consumption, and susceptibility to the common cold. Am J Public Health 1993; 83: 1277-1283.

25 Gwaltney JM Jr, Hayden FG. Psychological stress and the common cold. N Engl J Med 1992; 326: 644-645.

26 Arruda E, Pitkaranta A, Witek TJ Jr, Doyle CA, Hayden FG. Frequency and natural history of rhinovirus infections in adults during autumn. J Clin Microbiol 1997; 35: 2864-2868.

27 Makela MJ, Puhakka T, Ruuskanen O, et al. Viruses and bacteria in the etiology of the common cold. J Clin Microbiol 1998; 36: 539-542.

28 Monto AS, Sullivan KM. Acute respiratory illness in the community. Frequency of illness and the agents involved. Epidemiol Infect 1993; 110: 145-160. 